\title{
CUERPOS SENSIBLES: MUJERES EN LA ACCIÓN PERFORMÁTICA LATINOAMERICANA
}

\author{
Laura Janeth Rubiano Arroyo
}

\section{Resumo}

Neste artigo analisa-se a importância do corpo sensível como elemento vital da arte de ação ou performance, vinculando aos impactos sociais, políticos e culturais que hão tido as mulheres artistas latino-americanas e como isto há se convertido em um feito histórico e revolucionário na arte contemporânea, trazendo à memória deste escrito a artistas de países como a Colômbia, o México, o Brasil, a Argentina e Cuba, as quais hão demarcado uma pauta com seu próprio corpo, instalando-o em um espaço público ou privado, para ser o suporte feminista de finais do século, XIX e consequentemente dos séculos XX e XXI.

\section{Palavras-chave:}

Performance; Corpo Sensível; Mulheres; Feminismo.

\section{Abstract}

In this article discusses the importance of the body sensitive as a vital element of the art of action or the performance, by linking it to the impacts social, political and cultural that have had the Latin American women artists and how this has become a historical fact and revolutionary in the contemporary art, bringing to the memory of this written to artists from countries such as Colombia, Mexico, Brazil, Argentina and Cuba, which have been framed a pattern with his own body, by installing it on a public or private space, to be the feminist support at the end of the nineteenth century and consequently of the twentieth and twenty-first centuries.

\section{Palabras Clave:}

Performance; Sensitive Body; Women; Feminism.

\section{Resumen}

En este artículo se analiza la importancia del cuerpo sensible como elemento vital del arte de acción o el performance, vinculándolo a los impactos sociales, políticos y culturales que han tenido las mujeres artistas latinoamericanas y como esto se ha convertido en un hecho histórico y revolucionario en el arte contemporáneo, trayendo a la memoria de este escrito a artistas de países como Colombia, México, Brasil, Argentina y Cuba, las cuales han enmarcado una pauta con su propio cuerpo, instalándolo en un espacio público o privado, para ser el soporte feminista de finales del siglo XIX $y$ consecuentemente de los siglos $X X$ y XXI.

\section{Palabras Clave:}

Performance; Cuerpo Sensible; Mujeres; Feminismo.

El cuerpo puede definirse como la composición fisiológica que responde a acciones involuntarias e voluntarias dentro de un organismo en movimiento, llevando estas acciones físicas a estados concretos, para participar en todo un complemento de realidades orgánicas, sensitivas y psíquicas de lo que ocurre, en lo que podría denominarse un transcurrir cíclico, en el cual ese ir y venir adquiere una noción única, la de ser y sentirse unísono con los componentes que el espacio contiene, es decir, cuando el concepto de cuerpo se sumerge en la acción de concretar sus afirmaciones poéticas, puede adquirir una transformación en el ambiente donde desempeña esos niveles de apropiación, realizando desplazamientos consientes e inconscientes.

En este sentido hay que admitir que el espacio, considerado como un ambiente influenciable, tiene gran impacto en ese cuerpo que se desplaza, de tal forma que este puede responder como un elemento 
que se sumerge a esa misma homogeneidad de acontecimientos externos, que lo lleva a la búsqueda introspectiva de preguntas para dar un giro en el hábitat que sugiere su participación y muchas veces su modificación silenciosa.

Si estos eventos se hacen presentes tan solo en los cuerpos que transitan en una esfera cromática determinada, entonces ¿cómo sería la inclusión de esos cuerpos con una intervención directa, pactada y rodante en el espacio?, más allá de imaginar lo intenso o sublime que se presente esta cuestión, lo que realmente podría traspasar la barrera de este interrogante es la disposición que ya tienen los cuerpos cuando deambulan en los andenes, plazas, parques y vías, haciendo de un espacio de alteraciones sonoras un encuentro con el yo y el colectivo que entrega sus miradas al exterior.

Por lo tanto el gran encuentro se especifica en por qué el espacio se habita tan naturalmente e inevitablemente, es decir, como algo tan cotidiano puede inducir a la necesidad de hacer algo que muchas veces es co-habitable, en un sin número de acciones inéditas e inspiradas en el quehacer diario, resaltando ese encuentro con el cuadro común que se pinta día a día en una calle de vías desplazadas y cuerpos sumergidos en lo cotidiano o rutina, de ahí que el cuerpo del artista en el siglo $X X$ se convierte en una expresión abierta, que se hace presente dentro de lo que esta visible para transformar un espacio, en un transitar corporal hecho de arte.

De esta interacción cuerpo-espacio, lo urbano es su escenario principal, convirtiendo el afuera, lo aturdido, lo contaminado y muchas veces lo supresor en un camino de movimientos e imágenes cautivantes para quien camina y se encuentra con lo que ocurre en su observación, muchas veces ese espectador urbano se anima a hacer parte de lo que ve complementando con su cuerpo y gesto la obra que el artista quiere dar a conocer, considerando ese escenario como espacio urbano que en su significado puede ser estimado como una intervención abierta entre transeúntes, edificios, calles, andenes, casas, parques y plazas.

Frente a esa concepción de espacio escénico en el espacio urbano o público es apropiado resaltar que:

Cotidianamente, se organiza un orden social que es conformado por conductas cuasi-predecibles. Por ello, son los sujetos los que hacen de la ciudad un lugar practicado y habitado de constante fluctuación y movimiento y donde el puro acontecimiento los conecta con la arquitectura circundante que transitan a diario como escenario (GONZÁLEZ, 2013, p.729).

Es decir todo partiría de un punto en común el escenario público al servicio del individuo que transita en él, para convertirlo en una transformación de constantes ideas, críticas y muchas veces de encuentros furtivos o analógicos, donde los cuerpos que se movilizan tienden a ser parte de un ir y venir de posibilidades alternas, que muchas veces por el mismo contenido de la ciudad oprimida o imaginaria se olvidan del verdadero sentido del estar entre el espacio urbano, público y homogéneo.

Si bien se ha analizado el impacto trasmutable que ha tenido el cuerpo como el principal elemento de comunicación espacial, hasta tal punto que se convierte en un objeto visible que dialoga con una poética directa, creando a su vez una ilustración estética representativa y transformada de los antecedentes históricos que han marcado a la sociedad actual, es en ese instante que el cuerpo es un suministro de acontecimientos críticos y reflexivos, dejando en la interpretación del espectador- transeúnte las consecuencias y reflejos que este pueda llegar a destacar de lo que ve en la cera por dónde camina. Así el cuerpo comienza a cumplir una de las mayores expectativas en la época contemporánea comprendida entre la revolución francesa (1789) y la edad actual, resaltándose su efecto entre el escenario urbano en la década de los 60's con presentaciones artísticas como el performance ${ }^{1}$ y el happening ${ }^{2}$. Donde según Mauricio Marcelino Lima artista visual de la UNIPAN/UNIBAN:

Dentre os diversos movimentos de vanguarda
teremos alguns que foram importantes para mais
tarde a disseminação da arte das performances,
como o Dadaísmo, que já seguindo por uma
linha mais radical e ainda mais inovadora nega
a própria arte, criando obras que fugiam de
qualquer equilíbrio, usando sempre temas irônicos
e absurdos para chamar a atenção da sociedade.
Além dele teremos o Futurismo que busca o
dinamismo o movimento, e se vale dos manifestos
e declamações como uma nova ferramenta
de chamara atenção do público, tornando-se
importante para o desencadeamento não só das
Performances, mais também dos Happenings no
final do século XX. (LIMA, 2010, p.2) ${ }^{3}$. Por lo tanto se otorga una nueva perspectiva de la propuesta e interferencia del arte a nivel 
corporal, concibiéndose entonces en un arte más conceptual, abstracto y visualmente impactante, desde luego en los años 70's se abre camino a la acción pos-moderna al definir el cuerpo como un ser desplazado y desligado de la memoria común para hacer del efecto cotidiano una construcción y configuración sin límites y vértices. Haciendo énfasis en que:

\begin{abstract}
El espacio público, promete-aunque no asegura-un entorno diferente, en primer término la inclusividad, también el carácter igualitario que ofrece el acceso de cualquier persona, y finalmente, la apertura a la discusión que se proponga, sin restricción, y de la que pueden tomar parte todos los participantes. (GONZÁLEZ-VICTORIA, 2011, p.60).
\end{abstract}

Entendiendo como participantes a todos los cuerpos que transitan y se entrelazan con los acontecimientos en el espacio vivo y articulado, rescatando la imagen corpórea de una sociedad que se fundamenta en el afán de avanzar y permearse de nuevos suburbios, tecnologías, diferencias, espacios y tiempos.

El verdadero encuentro estaría acoplado con la sumatoria de desbalances y desequilibrios que los efectos sociales, políticos y económicos marcan a los urbanistas, tal vez este sea uno de los principales motivos del porque el cuerpo se convierte en un tabú social, dejando una huella de lo que realmente se quiere transformar y desligar de lo que es concreto y reglamentario, esto para el artista performatico enmarca su punto de partida, ser un tabú que se auto dirige y propaga su imagen indeterminada a un espectador de la zona urbana, que se inmoviliza para dar una consecuencia a ese performance que se dibuja ante su perspectiva sensitiva.

Pero más que un acontecimiento, muchos performances son un espejo del que transita, dejándolo a la intemperie interna, donde el ser observador, también lo convierte en ser observado por el artista que realiza la acción, de este modo se convierte en un juego de perspectivas que vitalizan el ahora y lo inevitable, palabras que serían comunes en el lenguaje artificial del espacio urbano y el espacio privado, si se analiza este punto de vista, se podría estar hablando de que todos los transeúntes son un performance andante, ya que cada acción que realiza tiene un comienzo y un fin en ese espacio público, vacío o privado, comprometiéndolo con un estado psicofísico y sensorial de lo que es, de lo que construye y de lo que delega como ser humano y ser social perteneciente a una cultura o a una etnia.

La mujer como un ser que revitaliza su esencia en el pensar y en el hacer, se une a esa ligación performatica en una crítica y autocrítica del verdadero sentido de su papel en esa sociedad marginada, si bien se ha observado a lo largo de las décadas que las mujeres se han construido como una lucha constante, a veces evolutiva, otras veces ambicionada y maltratada, dando un sin número de temáticas críticas y alternas a las artistas performaticas que deciden dar comienzo a su fuerte reflexión, reflejo y arte a la sociedad que las observa desde un afuera pero que internamente moviliza e plasma una idea circundante de lo que es ahora esa mujer polémica.

Esto comienza a ser un icono a finales del siglo XIX y XX, cuando la mujer latinoamericana como amante del arte se dispone a salir y a propagar su estado interno a una sociedad desligada de ese sagrado femenino, dando a la artista una coloración feminista, sumergiéndose en el ahora y en la sumatoria de la causa y el efecto de la sublevación femenina.

Parala ampliación de estos conceptos se haráénfasis en algunas de las artistas más representantes que durante los años 60's, 70's, 80's y 90's, hicieron polémica con sus performances, en países como México, Argentina, Brasil, Chile y Colombia, comenzando a transformar la escena en un cuerpo femenino andante y con un concepto impactante en la sociedad contemporánea, dejando sus raíces en lo que sería el llamado visible de la mujer contemporánea, abierta y con todo el interés de hacerse sentir a través de su mejor lenguaje, su cuerpo hecho de arte, en la actualidad .

\section{MARTHA MINUJÍN}

El performance latinoamericano nasce desde las corrientes vanguardistas, involucrando un sinfín de nuevos significados y formas de transportar la realidad a un escenario crítico y único.

De aquí el arte de acción argentino surge con una marcada raíz urbana y conceptual, y orientado a reflexiones socio-culturales amplias, como el impacto de los medios de comunicación masiva o la vida en las grandes urbes. (ALCÁZAR, 2011, 


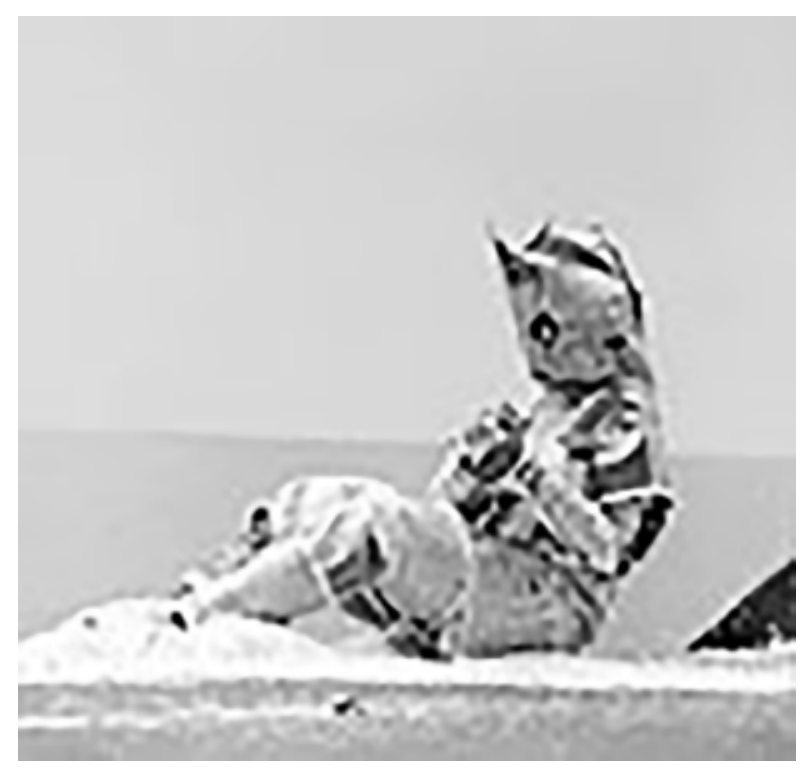

Figura 1 - Performance: Leyendo las noticias. Martha Minujín.1965. Buenos aires. Argentina.

Fuente: (http://cvaa.com.ar/02dossiers/accion/2_intro.php).

p.340), de este concepto nasce la conexión performatica de la artista Marta Minujín (Buenos aires Argentina, 1941), artista plástica proclamada como una de las incursoras del performance argentino, haciendo su mayor aporte desde 1960 en el escenario abierto, como se observa en la figura 1 , con su performance "leyendo las noticias", esta vez Minujín decide hacerse de puertas abiertas sobre el rio de la Plata. Argentina, develando un paisaje con un sentido abstracto profundo, al entrar a este espacio cubierta en papel periódico, tal vez lavando en un sentido onírico lo que se encuentra escrito y en su modo más profundo resaltando el arte de acción ${ }^{4}$ que estaba en la raíz del encuentro contemporáneo de la época.

\section{MARÍA TERESA HINCAPIÉ}

María Teresa Hincapié (1956-2008. Armenia. Colombia) es una de las artistas Colombianas que hace polémica por sus performances, donde plasma la realidad de la mujer, consiguiendo que sus imágenes retraten las angustias, vivencias, despedidas, encierros y discriminación de la mujer en la sociedad. Consiguiendo impermear frente al cuerpo y su alineación con el espacio, que en este caso sería un conjunto de acciones que se van transformando a medida que la artista va acompañando su acción corporal de elementos que subyacen para hacer una pieza entre objetos, cuerpo y esencia femenina. A pesar de que este

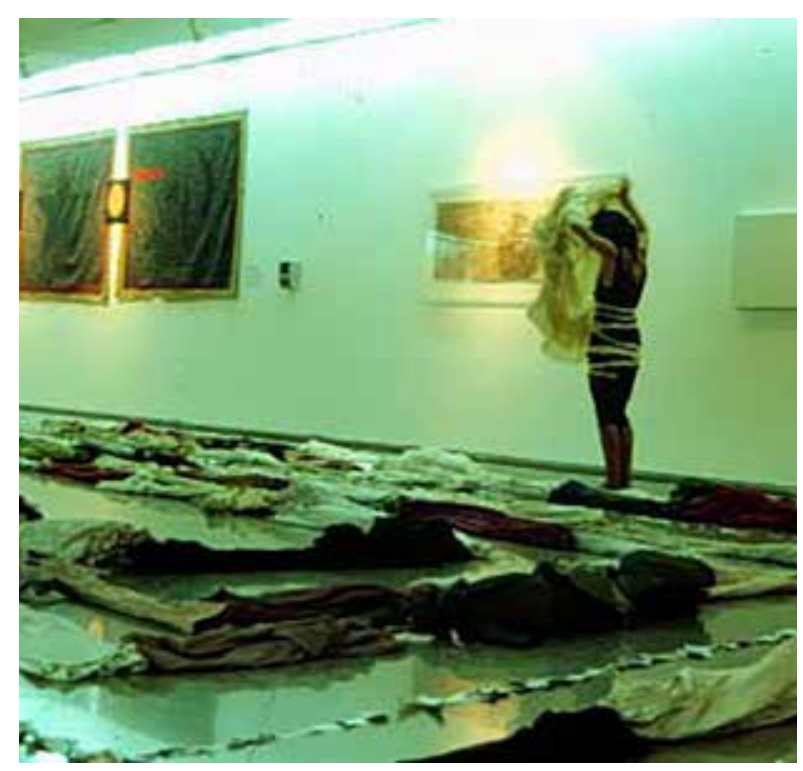

Figura 2 - Una cosa es una cosa. María Teresa Hincapié. 1990 Fuente: (http://www.leftmatrix.com/hincapielist. html).

trabajo fue realizado en el Salón Nacional de Artistas en 1990, sus performances también han sido expuestos en el espacio urbano, dejando que la artista vivencie en un espacio público todo lo que quiere transmitir a través del arte, la poética y el ser mujer.

\section{MÓNICA MAYER}

Mónica Mayer (1954. México) es una artista mexicana y activista del movimiento feminista de este país, concentrado su propuesta sobre los diálogos con aquellas mujeres que no podían decir públicamente lo que sentían en varios aspectos de su vida, desde su ser político, social, sexual y de derechos, esto lo plasmaba en cada una de sus obras permitiendo que en ellas ese tabú saliera al aire y más de una mujer, pudiera confrontar lo que sucedida y sentir esa libertad mientras veía sus performances.

La experiencia de Mónica Mayer es interesante pues refleja el contacto que existió con el movimiento feminista de los Estados Unidos y cómo influyó en artistas, que más tarde traerían sus experiencias a México. Mónica ingresa en 1978 al Feminist Studio Workshop en el Woman's Building en Los Angeles, California. Mónica recuerda cómo le impactó la forma de trabajo de esa institución: "El proceso educativo estaba basado en el formato de "pequeño grupo" tan utilizado por todo el movimiento feminista y pretendía desarrollar la creatividad y crear conciencia a través de dinámicas de grupo e investigaciones sobre las mujeres artistas en el 


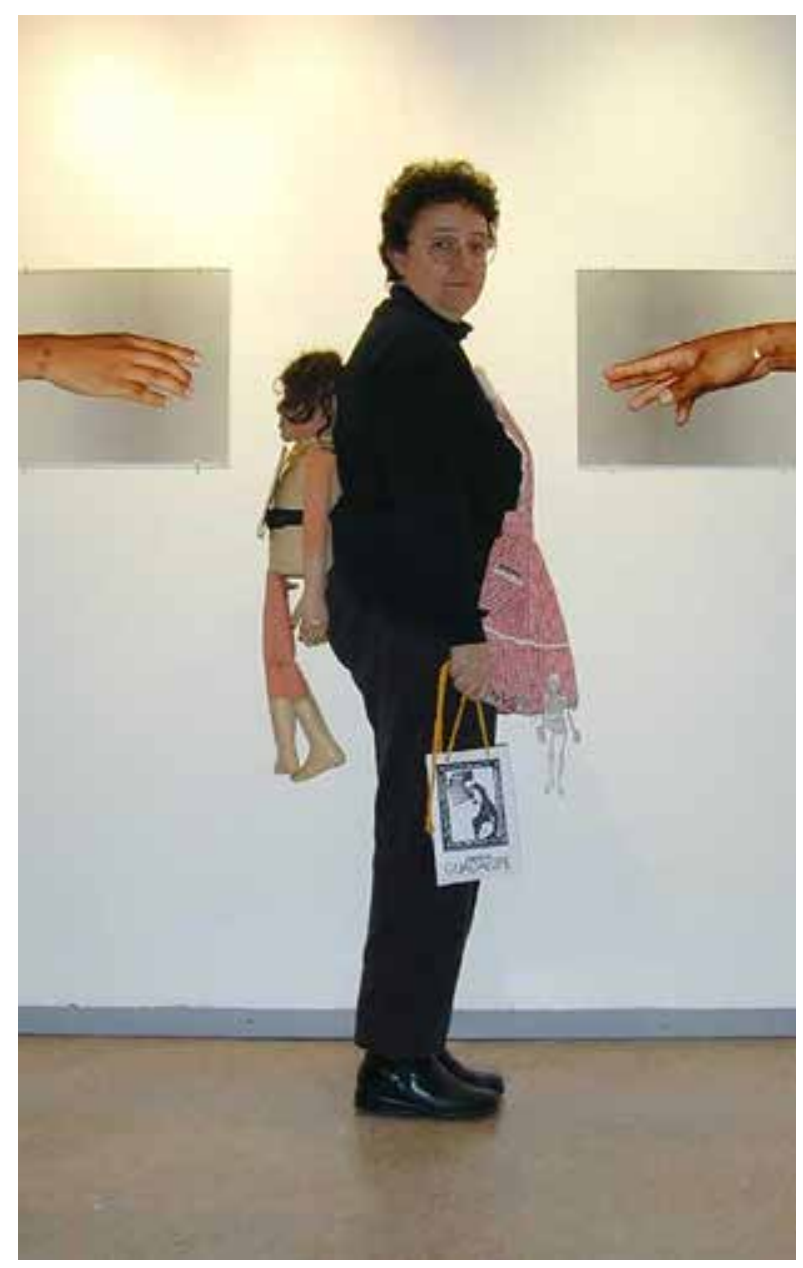

Figura 3 - Madre solo hay dos. Mónica Mayer. 2003. Fuente: (http://es.paperblog.com/madre-solo-haydos-monica-mayer-406588).

pasado. (JOSEFINA ALCÁZAR, 2001, p.4).

Llevando sus motivaciones a elaborar el performance "madre solo hay dos" ( figura 3), realizado en el Museo de las culturas Populares durante la X Bienal Guadalupano Lo Guadalupano, pretendiendo resaltar la imagen común de la madre, desde una alianza a la virgen de Guadalupe como un encuentro tradicional con su país de origen, queriendo resaltar los dos diferentes tipos de madres existentes, la madre devocional y la mala madre, involucrando a los espectadores a contar su historia personal con su madre y generar una catarsis interna con lo sucedido.

\section{LIGYA CLARK}

Ligya Clark (1920-1988. Balo horizonte. Brasil) pintora y escultura brasileña, llevando sus intereses a la fabricación de objetos estéticos que dispuestos en el espacio tienden a hacer relación

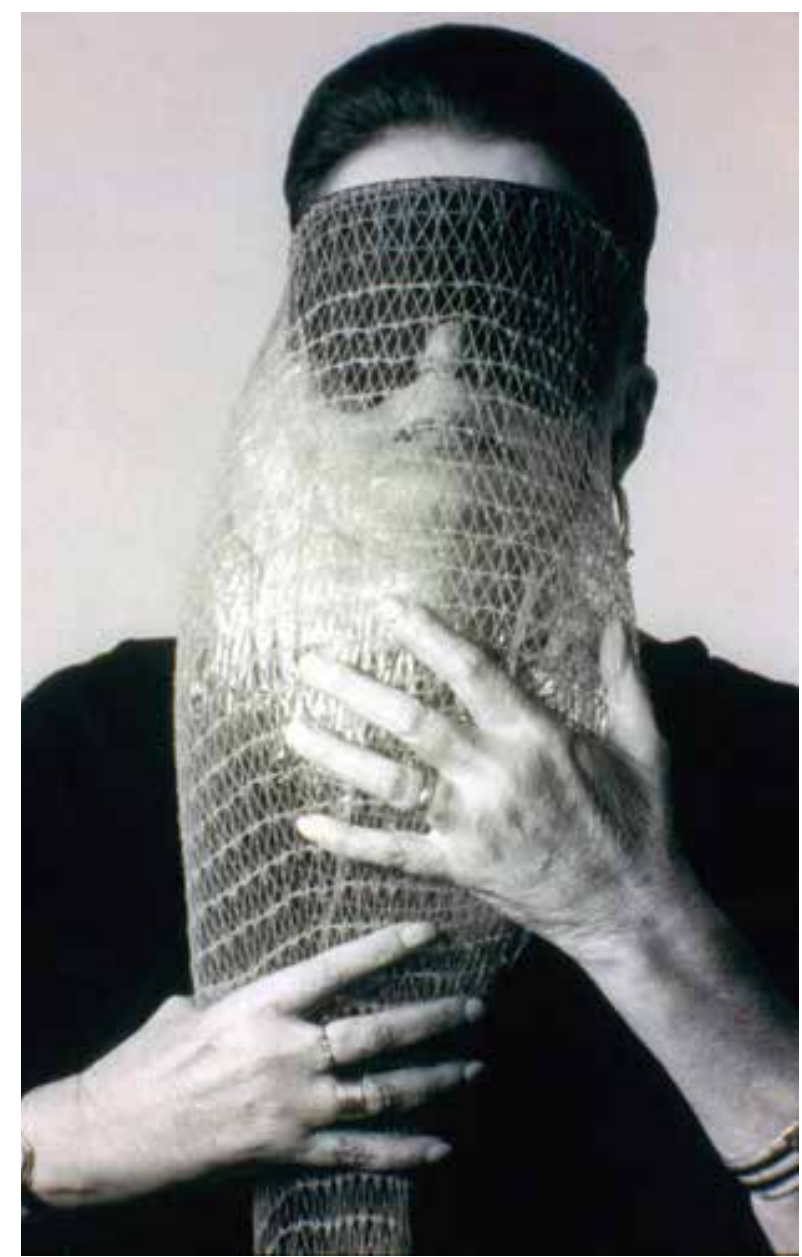

Figura 4 - Máscara abismo. Ligya Clark. 1968. Fuente: (https://www.moma.org/visit/calendar/ exhibitions/1462).

con los espectadores o participantes, su estilo puede ser definido entre la instalación y el body art, dejando que la artista experimente con lo orgánico y sensorial, lo que años más tarde, la llevaría a hacer un enlace psicoanalítico de sus obras convirtiendo su perspectivas en un arte terapia, que en lo profundo se alejaba de las connotaciones comunes del performance, el happening o el body art, dejando un espacio de exploración constante donde su actividad y protagonismo como artista central dejaba de ser el tema fundamental, dando relevancia a la exploración, sensibilización y cuerpo del espectador en relación con su objeto.

Por lo tanto según relata (MARTíNEZ DÍEZ, 2000, p.324):

En la fase sensorial de la obra de Lygia Clarlc podemos encontrar dos etapas, en la primera llamada «nostalgia del cuerpo», las personas encontraban su propio cuerpo por medio de objetos sin valor con los que realizaban ejercicios 
de sensibilización; en la segunda, los objetos eran pretextos para que surgiera la expresión del grupo. Para estas propuestas utilizaba gafas, guantes, cinturones y ropa con las que creaba ambientes que estimulaban la percepción, no como obras en sí. Poco a poco fue reduciendo los objetos a plásticos, hilos, elásticos, telas sin ninguna forma, formas que surgían por medio de la interacción de los participantes con los materiales. Con estas obras pretendía que en el acto de aprehensión, el redescubrimiento táctil induciera un trauma estimulante. Lygia Clark primero experimentaba estas acciones, luego lo hacían otras personas de forma individual, más tarde parejas, hasta llegar a las propuestas grupales que crecían a medida que aumentaban el número de las personas.

Denominándose incluso como no artista, intentaba hacer del espacio una transformación total, resaltándolo con objetos que generalmente son desechados, para que sus espectadores o el que cruzara en ese espacio sintiera un encuentro directo, improvisara y ampliara sus horizontes de exploración y creación junto con sus propuestas. Dentro de sus obras se destacan, mascara abismo (figura 4), guantes sensibles, mascara sensorial, respira conmigo y nostalgia del cuerpo, haciendo un dialogo en lo profundo o lo interno de ese colectivo participante.

Dentro del espacio público y el espacio privado como escenario de los performances, la mujer ha comenzado a travesar los esquemas de un cuerpo sexuado, marginado y abusado, para transformarlo en una obra de arte que conduce a la nueva realidad de una mujer polémica, que trasgrede la misma estética de su cuerpo para hacer frente a una acción social, la de vivenciar experiencias diversas que conducen a un punto, el cuerpo sensible que dialoga y se expone a las transformaciones vitales de una sociedad política en juego, invitando a los transeúntes, espectadores o participantes a hacer una pausa y experimentar de una forma abstracta lo cotidiano, lo orgánico, lo sensible, lo humano y lo voraz.

Son estos aspectos cívicos los que han involucrado el arte de acción o el performance a una continua imagen simbólica de la memoria colectiva, que después de la segunda guerra mundial crea un sin cesar de cuerpos sensibles dispuestos a hacerse sentir, destacando a artistas como:

1. Marina Abramovic, que en su performance Rhythm $O$ (figura 5) dejaba su cuerpo desnudo a disposición de los espectadores, colocando

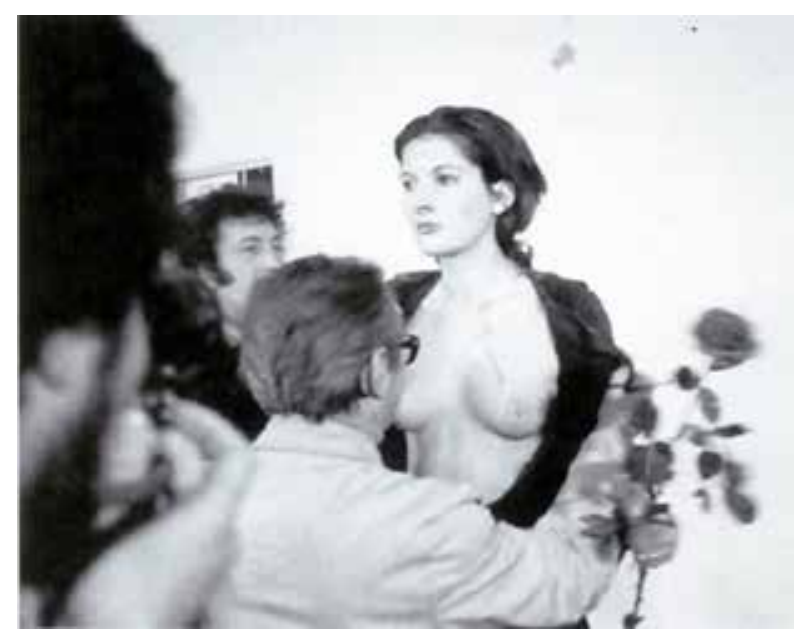

Figura 5 - Marina Abramovic. Rhythm 0. 1974. Fuente: (elaslifelive.tumblr.com).

objetos desde cuchillas, cuchillos hasta hojas a su alrededor, de tal forma que el espectador tomara ese objeto e hiciera algo en ella, a lo último colocaron en su mano un arma de fuego, lo que llevo a la finalización del performance por parte de la artista, quedando con cortadas y un sin número de objetos sobre su cuerpo.

2. Ana Mendieta, artista cubana que en sus obras refleja un sentido de aislamiento, como un cuerpo inherente que no pertenece a un lugar en específico, resaltado este fundamento en su obra Tree of life (figura 6) donde el paisaje, el barro y el árbol componen lo abstracto y resaltante de su cuerpo expuesto.

3. GracielaCamevale, artistaargentinavanguardista que en su obra declara el efecto fulminante del arte en relación a lo político, al artista y al espectador o público, haciéndose énfasis en su arte militante, así como su influencia en la sociedad. En su performance encierro y escape (figura 7), donde un número de personas que asistían al ciclo de arte experimental, fueron encerrados en la galería por la artista, con el fin de esperar lo que pudiera suceder con los espectadores en el interior, pero esta propuesta performatica termino al contrario de lo que esperaba la artista, ya que la euforia del encierro se reflejó en el exterior y un hombre decide romper el vidrio de la galería para sacar a las personas que se encontraban dentro, lo cual culmino con los performance en esa galería de esa fecha en adelante.

\section{Lorena Wolffer (1971. México), artista y activista}




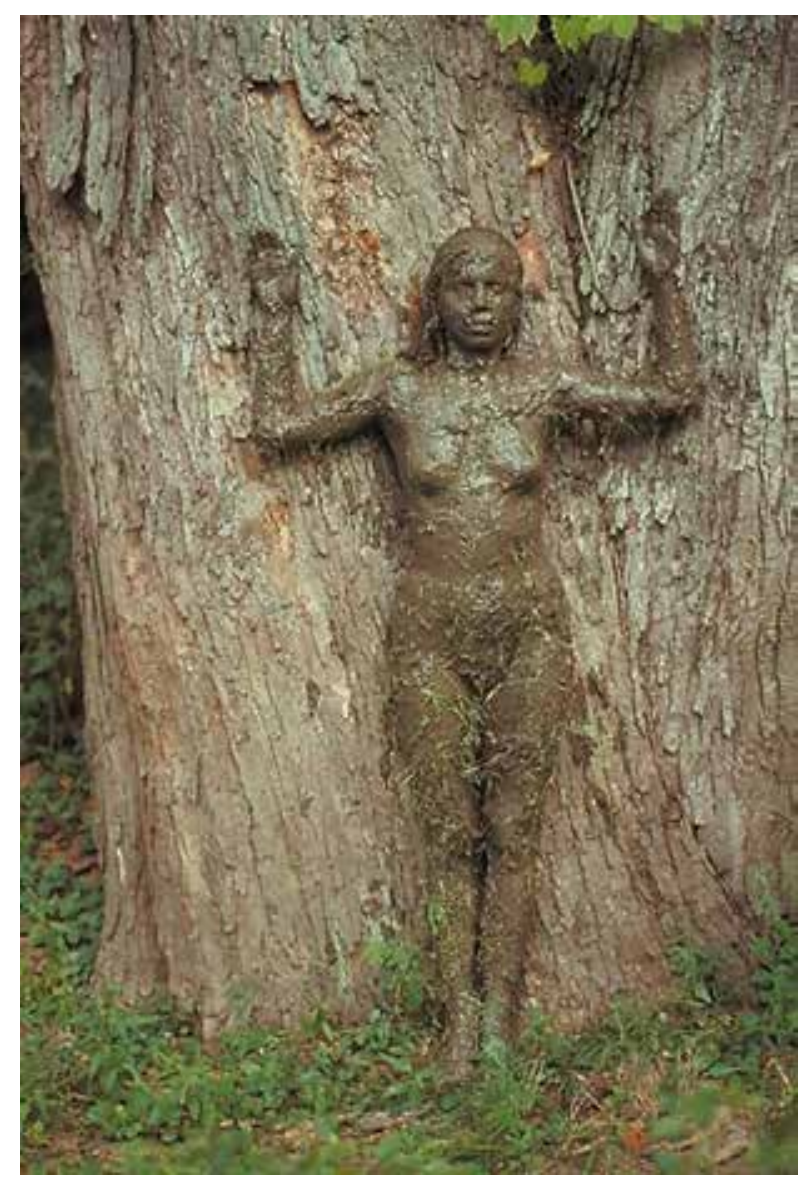

Figura 6 - Ana Mendieta. Tree of life. 1976.

Fuente: (http://artandwomensp2015.blogspot.com.br ).

del movimiento feminista de su país, que en sus performances logra enfatizar y hacer una denuncia pública de las voces femeninas, trasladándolas a su cuerpo, como un espejo que es expuesto y moldeado junto con la memoria de las mujeres violentadas, estas son las razones de base para crear sus performances, llevando incluso al espectador a un encuentro sobrecogedor y crítico de lo que ve, agudizando su observar con elementos puros como la sangre, estructuras quirúrgicas de metal, una voz en off que se hace participe para describir lo que en el tiempo transcurre, a veces por horas interminables. "La sangre es un elemento que Lorena utiliza de manera recurrente en muchos de sus performances. Lorena juega con el símbolo ambiguo que representa la sangre" (ALCÁZAR, 2011, p.345-346).

Por lo tanto se ha convertido en una de las artistas que vive a voz abierta el feminismo y su defensa, dejando al descubierto problemáticas políticas y sociales ocurridas en su país, como lo hace en sus performances Bañate en 1992, Territorio

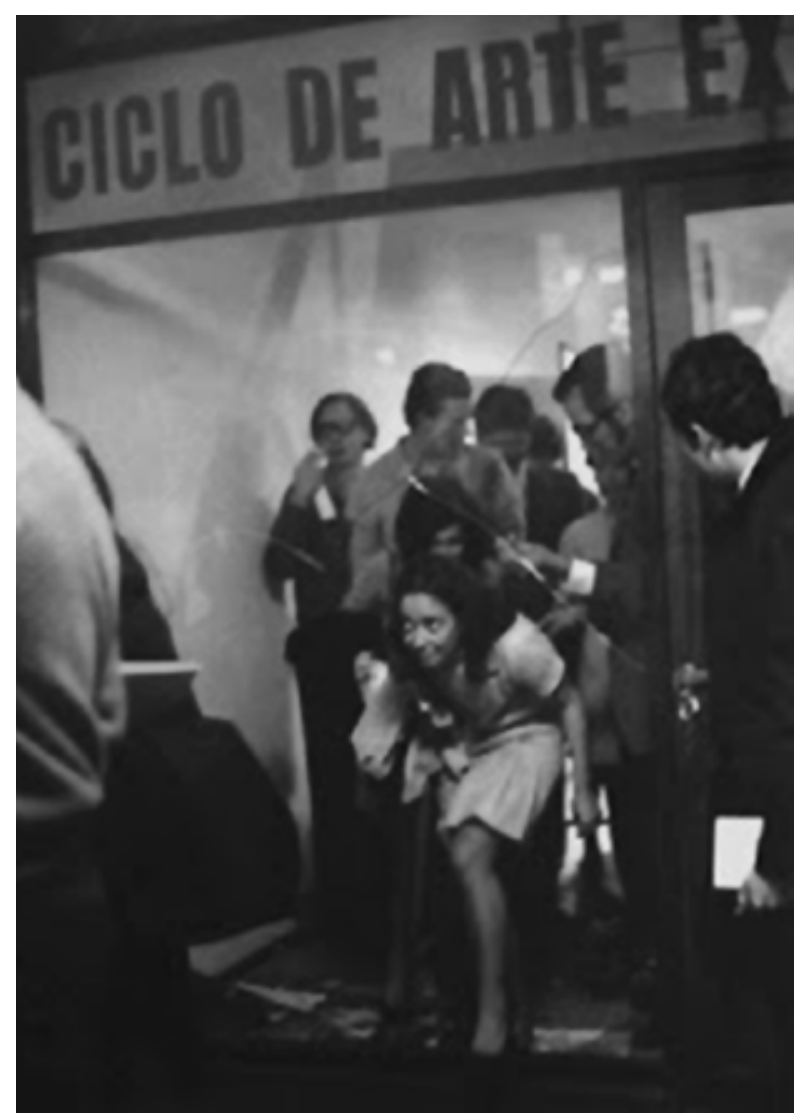

Figura 7 - Graciela Carnevale. Encierro y escape. 1968. Fuente: (http://slowanglewalk.blogspot.com. br/2010/11/encierro-y-escape.html).

Mexicano y Mientras dormíamos: el caso Juárez 2001-2004 (figura 8), en este último representa el feminicidio de Ciudad Juárez, México, haciendo un reconocimiento a las mujeres asesinadas y desaparecidas de esta ciudad, donde sus casos quedaron impunes y ella da vida a esa memoria, sentada semidesnuda en una tabla de morgue, hace notable un cuerpo lleno de laceraciones, las cuales van aumentando la hacerse heridas con un marcador en compañía de una voz en off que retrata cada caso de las mujeres asesinadas.

El cuerpo libertado es la expresión máxima de las artistas performaticas de finales del siglo $X I X$ y ente los siglos $X X$ y $X X I$, que a través de él, encuentran una respuesta a sus búsquedas internas, sintiéndose una voz abierta de aquellas mujeres suprimidas y calladas en la sociedad, su cuerpo entonces, partiría a ser un enlace con una memoria colectiva feminista y una denuncia corpórea frente a la cotidianidad deambulante.

Finalmente, el performance se convierte en 
un factor primordial de los cuerpos sensibles y feministas, siendo participes de un espacio que les permita dialogar con la idea de una sociedad igualitaria y justa, donde el artista navega con sus cualidades corpóreas y visuales, haciendo de la realidad social un momento a priori en la elección de sus temáticas.

Partiendo de esta idea el performance en el contexto sensible y feminista podría partir de tres vértices, la primera desde lo simbólico, que es la representación de aquellos signos vitales que demuestran la marginación de la mujer, recuperando los actos realizados cotidianamente, política y socialmente en contra de las mujeres, maltratadas, abusadas y asesinadas, la segunda es la trasgresión de los limites, en esta vértice las artistas utilizan imágenes impactantes que componen toda una escena catártica a través de su cuerpo, llevando temáticas como la violencia a un clímax visual elevado y la tercera son las instalaciones utilizadas, logrado que los elementos manipulados como sangre, jeringas, tablas de morgue, periódicos, letreros denunciantes, objetos desechados, barro, tierra etc., que ilustran sus performances sean un hecho vivaz y logren transformar la escena en un impacto político, social y cultural.

\section{NOTAS}

1. El performance es una manifestación artística que surge en la segunda mitad del siglo XX. Abarca una compleja y heterogénea gama de arte vivo que cruza las fronteras artísticas y disciplinarias en busca de nuevos lenguajes, nuevos espacios y nuevos materiales, para generar experiencias inéditas que enfatizan el proceso de creación y conceptualización frente al producto, y que hacen del cuerpo del artista su materia prima. "A lo largo de la historia los artistas han dibujado, esculpido y pintado el cuerpo humano. (ALCÁZAR, 2011, p.332).

2. Según el diccionario de arte y arquitectura el happening es un tipo de espectáculo, por lo general planeado cuidadosamente, aunque con cierto grado de espontaneidad, en el que un artista representa o dirige una función, combinando elementos del teatro y de las artes visuales. El término fue acuñado por Allan Kaprow en 1959, y su uso abarca una diversidad de fenómenos artísticos inventados.

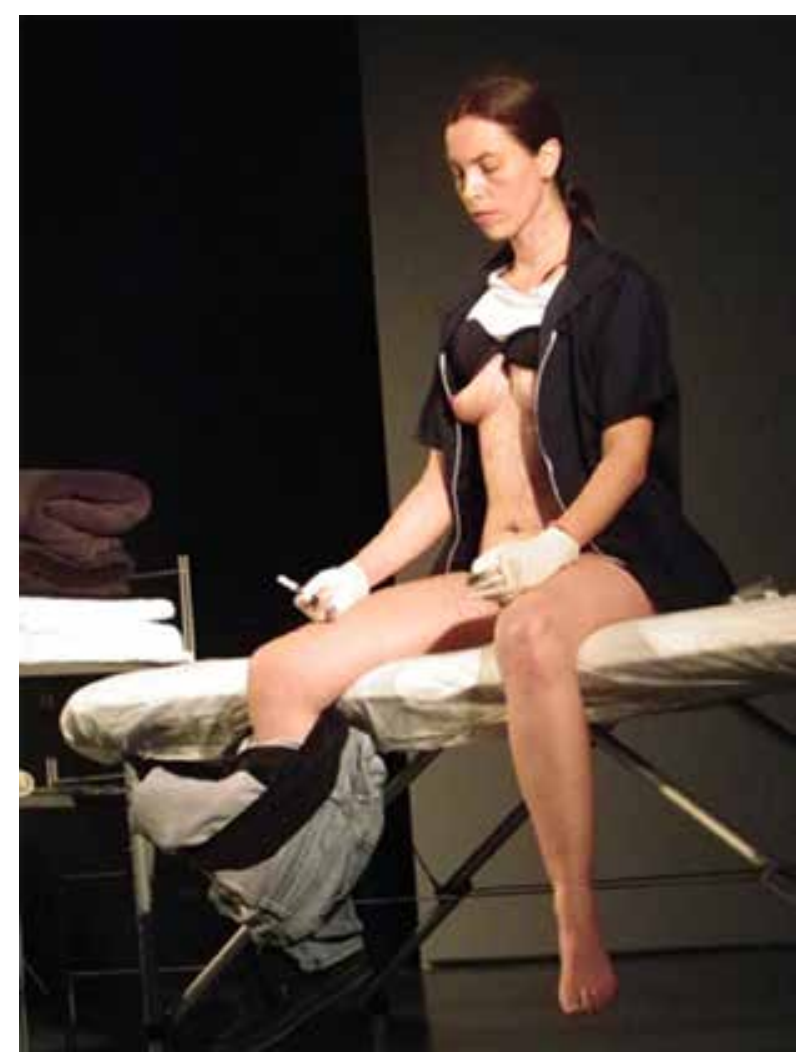

Figura 8 - Lorena Wolffer. Mientras dormíamos: el caso Juárez 2001-2004.

Fuente: (http://www.losangelespress.org/feminicidios-de-juarez-representados-como-performance-en-madrid).

3. Dentro de los diversos movimientos de la vanguardia tendremos algunos que fueron importantes para la divulgación del arte en el performance, como el Dadaísmo, que ya siguiendo en una línea radical e innovadora niega el proprio arte, creando obras que huían de cualquier equilibrio, usando siempre temas irónicos y absurdos para llamar la atención de la sociedad. Además de esto tendremos el Futurismo que busca el dinamismo y el movimiento, valiéndose de los manifiestos y declamaciones como una nueva herramienta de llamar la atención del público, tornándose importante para el desencadenamiento no solo de los performances, sino también de los Happenings al final del siglo XX. (LIMA, 2010, p.2). Traducción del portugués al español realizada por la autora.

4. Aunque las artes de acción sitúan su emergencia autónoma en el momento moderno de racional producción plástica, hay un previo recorrido desdelo arcaico, recorrido impreciso y extenso a partir dela emergencia de los dispositivos culturales, un continuo vaivén entre la ritualidad y el espectáculo, 
entre lo sacro y lo profano, y entre lo evidente y lo tácito. La segunda posguerra plantea un punto importante de inflexión en la discusión estética. Situarse en esta actitud posterior, que convoca experiencias potencialmente corporales, presenciales, exploratorias y contestatarias dentro del marco de lo urbano, implica asumir que el arte de la modernidad, llevado al límite de la abstracción, declina en la indeterminación de algunos de los discursos teóricos (propuestos en los manifiestos de las primeras vanguardias) y reconoce las limitaciones de lo objetual y la imposibilidad del retorno a lo figurativo. (GONZÁLEZ-VICTORIA, 2011, p.57)

\section{REFERÊNCIAS}

GONZÁLES, M.L. Intervenciones en el Espacio Público: Performance, Mirada y Ciudad. Revista brasileira de estudos da presença, Porto Alegre, v.3, n.3, p. 727-741, 2013.

GONZÁLES- VICTORIA, L.M. Artes de Acción: Re-significación del Cuerpo y el Espacio Urbano. Revista nodo, Cali. Colombia, v.5, n.10, p. 55-72, 2011.

\section{ALCÁZAR, J. Mujer, Cuerpo y Performance en}

América Latina. Centro de Investigación Teatral Rodolfo Usigli CITRU, México, p. 331-350, 2011. Disponible en :< http://www.flacsoandes.edu.ec/ sites/default/files/agora/files/1215033856. mujeres_cuerpo_y_performance._por_josefina_ alcazar_3.pdf>. Acceso en: 4 jun. 2015

LIMA, M.M. Performance: O corpo como expressão máxima e singular. II Seminário Nacional em Estudos da Linguagem: Diversidade, Ensino e Linguagem, Paraná, p. 1-12, 2010. Disponible en :< http://cac-php.unioeste.br/eventos/iisnel/ CD_IISnell/pages/simposios/simposio>. Acceso en: 4 jun. 2015

ALCÁZAR, J. Mujeres y Performance. El Cuerpo como Soporte. Centro de Investigación Teatral Rodolfo Usigli CITRU, México, p. 1-12, 2001. Disponible en $:<$ http://lasa.international.pitt. edu/Lasa2001/AlcazarJosefina.pdf>. Acceso en: 5 jun. 2015

MARTÍNEZ DÍEZ, N. Lygia Clark. Arte, Individuo y Sociedad, Madrid, p. 321-328, 2000. Disponible en $:<\mathrm{http} / / /$ www.arteindividuoysociedad.es/
articles/N12/Noemi_Martinez.pdf>. Acceso en: 5 jun. 2015

\section{Sobre a autora}

Possui graduação em Licenciatura em Danças e Teatro - Universidad Antonio Nariño em Bogotá, Colômbia (2013). A sua formação acadêmica e experiência laboral estão baseadas no conceito de artista integral, trabalhando com as diferentes linguagens artísticas como a dança (colombiana, contemporânea, técnica de ballet, butho, son cubano, tango, entre outras), o teatro (colombiano, técnica de teatro oriental, experimental, contemporâneo e performance), a música (técnica vocal, tradicional colombiana, violão e percussão) e as artes plásticas (desenho da figura humana, criação de máscaras, maquiagem corporal, instalações performáticas, cenografia e desenho de figurino. Participou como atriz, dançarina, designer de figurino e maquiagem em vários eventos na Colômbia. Foi diretora, coreografa, docente, artista e atualmente é especialista em anatomia do movimento, área na qual está situada a sua pesquisa de mestrado em Artes. 